\title{
Rodrigo Borba
}

Universidade Federal do Rio Grande do Sul

\author{
Ana Cristina Ostermann
}

Universidade do Vale do Rio dos Sinos

\section{Gênero ilimitado: a construção discursiva da identidade travesti através da manipulação do sistema de gênero gramatical}

Resumo: Este estudo investiga a manipulação do sistema de gênero gramatical entre travestis profissionais do sexo do Sul do Brasil. Verificou-se que há uma preferência êmica do grupo por formas gramaticais femininas. Porém, as tensões ideológicas e corporais que circundam as travestis forçam-nas a utilizar o masculino em contextos específicos. As travestis empregam o masculino gramatical para 1) produzir narrativas sobre o período anterior às suas transformações corporais; 2) reportar discursos produzidos por outros ao falar de travestis; 3) falar de si em suas relações familiares; e 4) distinguir-se de outras travestis com as quais as falantes não se identificam. Assim, o estudo demonstra como essas travestis usam o gênero gramatical do Português como um recurso lingüístico para manipular suas identidades e as identidades da comunidade a que pertencem.

Palavras-chave: travesti; identidade transgênero; gênero gramatical; corporificação.

Copyright (C) 2008 by Revista Estudos Feministas.

\footnotetext{
1 Uma versão substanciada dos resultados deste estudo foi publicada em língua inglesa em Gender and Language, v. 1, p. 131-147, 2007.

2 Penelope ECKERT e Sally MCCONNELL-GINET, 1992, 1999 e 2003; Janet HOLMES e Miriam MEYERHOFF, 1999; e Ana C. OSTERMANN, 2003 e 2006.
}

\section{Introdução}

Este estudo investiga como travestis que se prostituem em uma região urbana do Sul do Brasil utilizam fluidamente o sistema gramatical de gênero como uma ferramenta para fragmentar discursivamente suas identidades e, assim, construir uma plêiade de significados sociais sobre suas posições sociais. ${ }^{1}$ Mais especificamente, investigam-se as práticas discursivas de uma comunidade de prática ${ }^{2}$ (CdeP, doravante) constituída por travestis que se prostituem em uma região urbana do Sul do Brasil com o intuito de colocar sob escrutínio como elas manipulam o sistema gramatical 
3 Thomas MAUSS, 1996.

${ }^{4}$ Deborah CAMERON, 2001; Luiz Paulo MOITA LOPES, 2002 e 2003; e Mary BUCHOLTZ e Kira HALL, 2003, 2004 e 2005.

${ }^{5}$ Don KULICK, 1999, p. 616.

${ }^{6}$ Marcos R. BENEDETTI, 2005.

7 Wiliam S. Peres cunha o termo travestilidade (em oposição a travestismo), pois, segundo o autor, esse termo contempla "a imensa complexidade das formas de expressão travesti existentes, considerando a heterogeneidade dos modos de ser no mundo que é configurado pela sub-cultura travesti" (PERES, 2004, p. 120). Esse termo será utilizado neste trabalho para se referir à identidade travesti.

${ }^{8}$ São exemplos dessa literatura: a Lapa no Rio de Janeiro (Hélio SILVA, 1993 e 1996), as ruas e as moradas conjuntas de travestis em Salvador (KULICK, 1998), bares gays de Florianópolis (Marcelo J. OLIVEIRA, 1994) e o fundão, a zona de prostituição de travestis, em Porto Alegre (BENEDETTI, 2000 e 2005).

9 Com exceção de Don KULICK, 1996, 1997 e 1998.

10 Jennifer COATES, 1998, p. 301.

11 Guacira L. LOURO, 2001.

12 Thomas CSORDAS, 1990; e Rodrigo BORBA e Ana C. OSTERMANN, 2007.

13 Judith BUTLER, 2003. de gênero para construir suas identidades a partir de ideologias dicotômicas sobre masculinidade e feminilidade.

Grosso modo, travestis são indivíduos biologicamente masculinos que, através da utilização de um complexo sistema de techniques du corps, ${ }^{3}$ moldam seus corpos com características ideologicamente associadas ao feminino. Levando em consideração que a identidade é, em grande medida, um fenômeno lingüístico, ${ }^{4}$ pretende-se entender qual a relação mantida entre linguagem e identidade(s) de gênero nessa comunidade de travestis. Por sua transitoriedade pelos pólos da dicotomia de gênero, as travestis parecem ser capazes de subverter associações naturalizadas entre formas lingüísticas e categorias sociais ao se utilizarem de discursos sobre essas categorias em suas interações. Assim, sujeitos que subvertem práticas semióticas para construção de seu gênero social entretêm com a linguagem uma relação de "différance mútua, de fluidez mútua que excede significados fixos e se mantém sempre plural, continuamente rompendo a marcação de fronteiras". ${ }^{5}$

Os/as pesquisadores/as que se aventuraram no universo trans ${ }^{6}$ para entender o fenômeno da travestilidade ${ }^{7}$ tentaram fazê-lo ao contextualizar as práticas travestis em seus lugares sócio-culturais específicos. ${ }^{8}$ Esses estudos ${ }^{9}$ analisam a visão que as travestis têm de si mesmas e como elas se constroem como indivíduos generificados, desconsiderando um aspecto altamente relevante ao processo de construção das identidades sociais: a linguagem e seus usos dentro de CdePs específicas. Assim, a maioria dos estudos sobre as travestis brasileiras deixa para trás o fato de que "a linguagem tem um papel crucial na estruturação de nossa experiência". ${ }^{10}$

É, portanto, a necessidade de entender como os/as transgêneros utilizam a linguagem para se alocar nas e/ou transcender as fronteiras dos gêneros ${ }^{11}$ que justifica 0 presente estudo. Basilar para os argumentos que apresentamos é o conceito de corporificação, i.e., embodiment. ${ }^{12}$ Corporificação, para os propósitos deste estudo, refere-se à apropriação de signos corporais e sóciopolíticos de gênero e sexualidade elaborada pelos/as transgêneros nas mais diversas culturas. Ao moldar seus corpos para adquirir formas corporais e práticas simbólicas desejadas, os/as transgêneros sobrepõem sistemas de signos que os/as produzem como culturalmente trans, i.e., ao transformar seus corpos, transgridem suas limitações biológicas, construindo, dessa forma, posições sociais salientes nas sociedades das quais participam. A corporificação é o que habilita os/as transgêneros a construir performances de gênero ${ }^{13}$ que contrastam com suas determinações biológicas através do uso de seus corpos e 
14 Todos os nomes de travestis, lugares, instituições, mencionados durante o texto são pseudônimos para salvaguardar as identidades dos sujeitos envolvidos na pesquisa.
15 Kira HALL e Veronica O'DONOVAN, 1996; Anna LIVIA, 1997; Matti BUNZL, 2000; ECKERT e MCCONNELL-GINET, 2003; e BUCHOLTZ E HALL, 2005.

${ }^{16}$ Alessandro DURANTI, 2001.

17 BUTLER, 2003. da linguagem. No que se refere às travestis, é a performance de um gênero feminino sobre um corpo que mantém marcas do masculino que faz de suas identidades serem social e lingüisticamente maleáveis. Dessa forma, com este estudo, tentamos criar inteligibilidade sobre a construção discursiva da travestilidade a partir das modificações corporais efetuadas por travestis na Cidade do Sul. ${ }^{14}$ Mais significativamente, descrevemos como o uso do sistema gramatical de gênero é influenciado pelas posições de gênero transitórias das travestis; transição essa calcada, principalmente, em suas transformações corporais.

\section{Rompendo associações entre formas lingüísticas e categorias sociais}

O sistema gramatical de gênero, nas diferentes línguas que o utilizam, constitui uma ferramenta poderosa para a produção de identidades sociais. ${ }^{15}$ Línguas como Português, Francês, Espanhol e Hindu expressam gênero como uma categoria explícita ${ }^{16}$ em sua morfologia e sintaxe. Dessa maneira, falantes têm o sistema gramatical de gênero como um recurso importante para construir a si próprios, seus/ suas interlocutores/as e aqueles/as sobre quem falam como seres generificados. Esse processo é fortemente baseado em práticas semióticas, culturalmente ligadas a categorias sociais específicas, que fazem com que os/as falantes se refiram a si mesmos/as e a seus/suas interlocutores/as a partir de suas performances de gênero. ${ }^{17}$ Contudo, esse processo de generificação lingüística torna-se altamente polissêmico no discurso de sujeitos que deslocam as barreiras dos gêneros e sobrepõem práticas semióticas para a fabricação do feminino e do masculino: as/os transgêneros.

Indivíduos transgêneros são salientes em qualquer sociedade, pois suas manipulações de símbolos sociais, culturais, sexuais e corporais sobrepõem camadas de significados que, sem uma análise minuciosa, são de difícil apreensão. ${ }^{18} \mathrm{Os} /$ as transgêneros têm papéis relevantes para a variação lingüística, o que está intimamente relacionado com suas práticas sociais. O cruzamento das fronteiras dos gêneros parece levar esses sujeitos a subverter limitações lingüísticas para manufaturar suas identidades.

Lingüistas têm extensivamente investigado como falantes de diferentes línguas podem produzir inovações identitárias ao romper associações naturalizadas entre formas lingüísticas específicas e categorias sociais particulares. ${ }^{19}$ Esse é o caso, por exemplo, do estudo sobre as práticas discursivas em um grupo de hijras (eunucos) indianas elaborado por Kira Hall e Verônica O'Donovan. ${ }^{20}$ Segundo as autoras, as hijras manipulam o sistema 
${ }^{21}$ HALL e O'DONOVAN, 1996, p. 258.

22 HALL, 2002, p. 149.

${ }^{23}$ LIVIA, 1997.

${ }^{24}$ LIVIA, 1997, p. 352. gramatical de gênero para evocar "uma grande gama de discursos sociais sobre poder e solidariedade, diferença e dominação" ${ }^{21}$ Nessa perspectiva, o gênero lingüístico não somente expressa diferenças de gênero; ele também revela possibilidades identitárias.

Como as pesquisadoras indicam, as hijras usam formas gramaticais femininas para construir relações de solidariedade. As formas masculinas, por sua vez, são empregadas para construir relações de poder e dominação. Ao utilizar o masculino gramatical, as falantes distanciamse de hjiras com as quais elas não se identificam e, assim, fortalecem a superioridade da falante. Hall observa que, "quando a falante deseja expressar distância social entre si e outra membra da comunidade, seja por respeito (como para sua guru) ou desgosto (como por uma hijra inimiga), ela irá freqüentemente referir-se àquela pessoa no masculino". ${ }^{22}$

Seguindo perspectiva similar, Anna Livia ${ }^{23}$ analisa a autobiografia da transexual francesa Georgine Nöel para investigar a fluidez de formas gramaticais masculinas e femininas no decorrer do texto. Embora Nöel afirme ter sempre sido feminina em sexo, seu uso do sistema gramatical de gênero em francês é ambíguo. Essa ambigüidade, segundo a autora, está ligada à situação social na qual Nöel se descreve e aos papéis que ela assume durante o texto. Parece que "Nöel usa a oposição binária do sistema lingüístico francês [...] para descrever suas mudanças de humor, atitude e identificação". ${ }^{24}$

A autora afirma que indivíduos transgêneros empregam os gêneros gramaticais para alcançar diferentes objetivos em momentos diferentes. O uso de formas masculinas e/ou femininas para descrever as atividades de Nöel em sua infância, por exemplo, indica as mudanças de atitude de Nöel durante sua narrativa. Quando a transexual francesa descreve-se pedalando sua bicicleta para salvar seus primos na guerra, ela parece orgulhosa de seu heroísmo e usa o masculino gramatical para se referir ao evento. Por outro lado, quando Nöel é encontrada apanhando flores no caminho da escola com suas amigas, ela se descreve no feminino para distanciar sua persona do mundo dos meninos. Nöel também utiliza formas masculinas para expressar seu desgosto em relação a seu corpo (ainda) biologicamente masculino. Assim, a alternância de formas masculinas para femininas expressa o triunfo do eu feminino de Nöel sobre suas determinações biológicas. Paradoxalmente, a mudança do feminino para o masculino gramatical parece demonstrar a frustração com relação ao seu corpo masculino assim como sua superioridade e autoridade na sociedade como homem. Como afirma Livia, 
${ }^{25}$ LIVIA, 1997, p. 365.

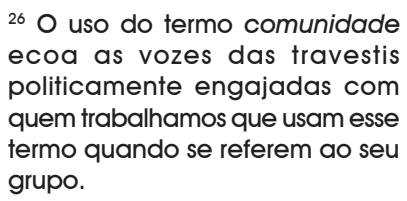

${ }^{27}$ Richard PARKER, 2002.

${ }^{28}$ MAUSS, 1996. os/as transgêneros "atuam como mediadores dos gêneros, revelando recursos disponíveis no sistema de gênero aos quais identidades mais tradicionais têm pouco acesso". ${ }^{25}$

Observe que as hijras indianas, a transexual francesa e, como descrevemos neste artigo, as travestis de Cidade do Sul alternam códigos na tentativa de ocupar lugares específicos em seus mercados identitários. Isso pode ser motivado por seus corpos limiares. Os/as transgêneros, via suas práticas corporais e lingüísticas, participam de uma miríade de discursos de gênero que os/as capacitam a discursivamente posicionarem-se de variadas maneiras.

\section{Dados para o presente estudo}

Os dados foram gerados durante um período de 12 meses em uma comunidade ${ }^{26}$ de travestis que se prostituem na Cidade do Sul. Os dados analisados fazem parte de um corpus coletado durante trabalho de campo no qual as travestis eram acompanhadas em variados eventos. A entrada de campo na comunidade foi apoiada por membras da ONG Liberdade, uma organização não-governamental que trabalha com as travestis na Cidade do Sul.

Para o presente estudo, analisamos sete entrevistas com travestis que foram gravadas em áudio e transcritas para a análise, totalizando aproximadamente 10 horas e 30 minutos de dados em áudio. As interações foram gravadas na sede da Liberdade. Além disso, o corpus é composto por: gravações em áudio de conversas espontâneas na sede da Liberdade, gravações de conversas espontâneas entre travestis e ativistas da Liberdade durante intervenções para entrega de preservativos nas áreas de prostituição da Cidade do Sul, notas de campo sobre as práticas travestis dentro e fora das zonas de prostituição, e gravação de uma reunião durante a qual os resultados da pesquisa foram discutidos com as travestis. É importante enfatizar, porém, que as análises apresentadas aqui são principalmente baseadas nas entrevistas realizadas com as travestis.

\section{$(\mathrm{Re})$ construindo corpos, identidades e posições sociais}

As travestis, por subverterem as práticas semióticas disponíveis para produção de gênero social, estão entre as figuras mais características do mundo urbano gay do Brasil. ${ }^{27}$ A utilização de um complexo sistema de techniques du $\operatorname{corps}^{28}$ para a aquisição de um novo corpo e, conseqüentemente, uma nova identidade é o traço diacrítico da travestilidade. Sua mobilidade por diferentes esferas do gênero e 
${ }^{29}$ Pierre BOURDIEU, 1985.

${ }^{30}$ Paul KROSKRITY, 2000.

${ }^{31}$ BENEDETTI, 2000 e 2005.

32 Ver BENEDETTI, 2000 e 2005 , para uma descrição mais detalhada sobre os usos de maquiagem, o cuidado com os pêlos, tratamentos cosméticos e uma miríade de outras técnicas utilizadas para a aquisição de formas femininas.

${ }^{33}$ BENEDETTI, 2000.

${ }^{34}$ As convenções utilizadas nas transcrições apresentadas no texto estão detalhadamente descritas no Apêndice. da sexualidade lhes permite transitar por variados discursos sobre as posições de sujeito disponíveis na sociedade. Assim, a configuração de um habitus ${ }^{29}$ travesti, com suas especificidades sociais, físicas e culturais, é construída na fluidez de significados elaborados em suas práticas sociais, suas trocas sexuais, seu corpo e, como o presente estudo tenta demonstrar, na maneira com que as travestis utilizam a linguagem para fabricar seu repertório de identidades. ${ }^{30}$

Entre as travestis, a percepção do corpo e sua fabricação constituem sua identidade social e seu processo e fabricação como pessoa. ${ }^{31} \mathrm{O}$ corpo travesti é treinado minuciosamente para adquirir características associadas às mulheres. Desde a maneira de mexer nos cabelos até as formas corporais, as travestis ostentam um complexo sistema de técnicas para a construção do feminino. ${ }^{32}$

Tratamentos hormonais parecem constituir um ritual de passagem ${ }^{33}$ através do qual o devir travesti é conquistado. Assim, pode-se dizer que o processo de hormonização corporal elaborado pelas travestis é um dos traços diacríticos da travestilidade. Como disse Marcela, uma das informantes da pesquisa, "travesti que é travesti é hormonizada!".

Não há conversa entre travestis que não verse sobre suas experiências com hormônios. Ao ter a oportunidade, elas compartilham os conhecimentos adquiridos através de suas experiências com essas substâncias que, segundo as travestis, são a verdadeira fonte de feminilidade, como se pode verificar no excerto abaixo. ${ }^{34}$

\section{Excerto 1 [LIB9503 - CLCMR]: hormônios vs. natureza}

160 CYNTHYA: = Eu sinceramente assim ó (.) Tirei (os pêlos)

161 faz quinze dias e tô esperando desesperada né?

162 ((bate na mesa e suspira)) $>$ Tudo pinicando $<$

163 Cera é maravilhosa né? [mas] como a

164 testosterona $=$

165 CASSIANA:

$[\mathrm{mhm}]$

166 CYNTHYA: $=$ Tem funcionado muito ultimamente- $=$

167 LUCIANA: $=$ BAH $::=$

168 CYNTHYA: = Me-ni-na o (pêlo) não nasce tudo e eu tô

169 assim só na $\mathrm{G} 2$ desesperada=

170 LUCIANA: =Pro que que a a testoterona briga com com com

171 com o hormônio?=

172 CYNTHYA: = Porque é o nosso biológico e a produção de XXX 


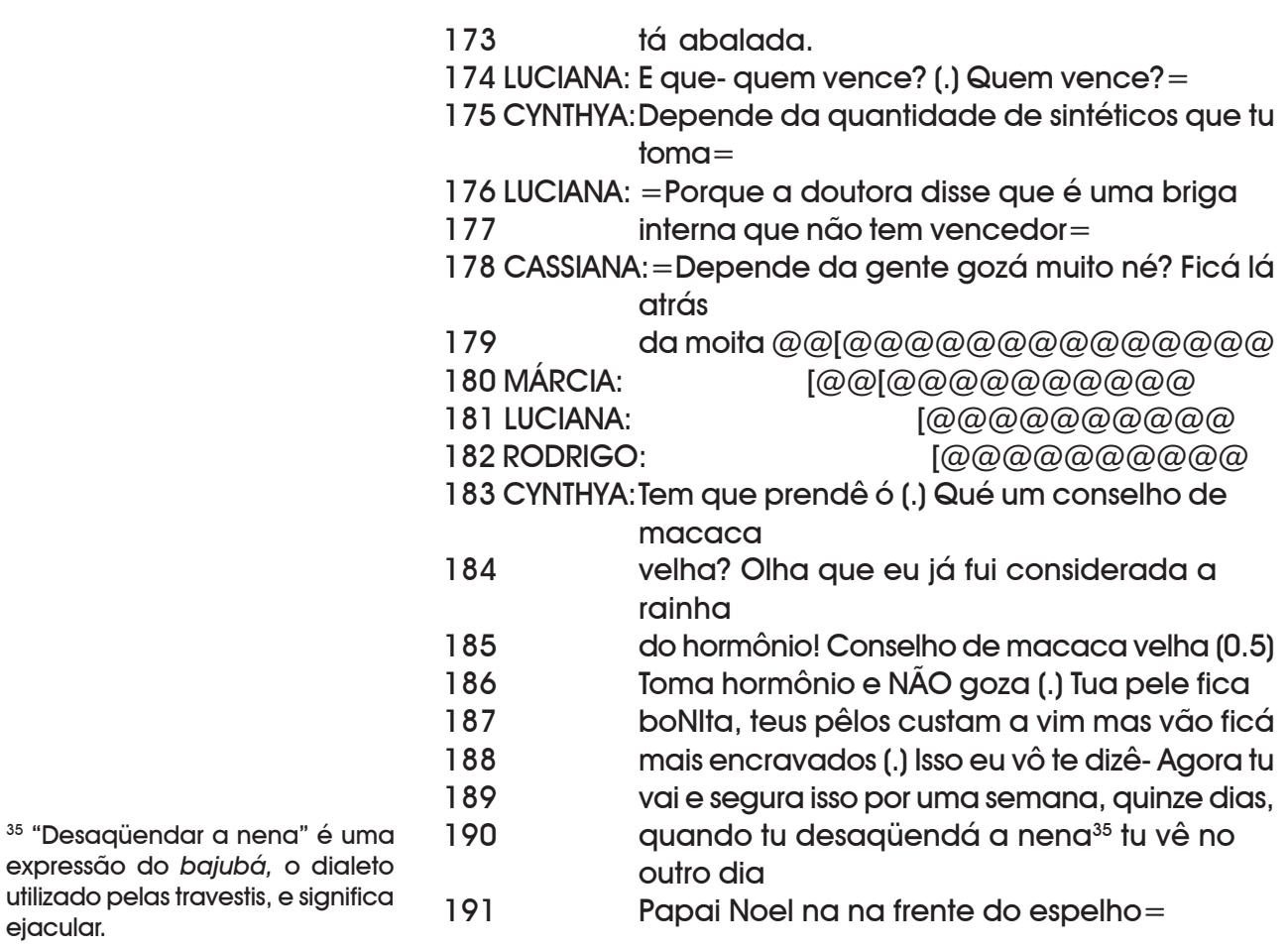

A relação de amor e ódio entre as determinações biológicas das travestis e as intervenções químicas em seus corpos é um tópico muito freqüente em interações nesse grupo. Nas linhas 160-164 do Excerto 1, Cynthya descreve sua dificuldade em manter sua figura feminina quando a "testosterona funciona muito". A briga interna à qual Luciana se refere na linha 170 parece ser o grande desafio nas vidas das travestis. Como os níveis de testosterona podem interferir nos efeitos trazidos pelos hormônios, as travestis às vezes têm de se privar do prazer sexual numa tentativa de manter a substância em seus corpos. O vencedor dessa briga interna, como as travestis mesmas costumam afirmar, depende do quanto se ejacula. Nessa perspectiva, o sêmen parece ser concebido como o veículo através do qual sua feminilidade pode deixar seus corpos. Para evitar perder suas formas femininas, as travestis da CdeP sob escrutínio acreditam que devem manter seu esperma no interior de seus corpos (linhas 186-191) e, em nome da feminilidade, deixam de ejacular por dias, até mesmo semanas, para manter suas formas corporais.

Outra prática empregada por travestis na construção de uma nova identidade é o uso de silicone industrial e/ou cirúrgico. A decisão de se submeter à injeção de qualquer 
${ }^{36}$ BOURDIEU, 1985 e 1986.

37 Ver KULICK, 1998, e BENEDETTI, 2005, para descrições mais detalhadas de sessões com bombadeiras.

${ }^{38}$ Anthony GIDDENS, 1993. dos tipos de silicone depende de muitos fatores, sendo a impossibilidade financeira o fator mais freqüente. É importante notar, no entanto, que aquelas travestis que têm seus corpos moldados por silicone parecem possuir mais capital físico, ${ }^{36}$ o que é essencial nas vidas das travestis que trabalham como profissionais do sexo.

Como mencionado acima, há dois tipos de silicone disponíveis para uso, os quais toda travesti conhece detalhadamente. O mais comum (por ser economicamente acessível) é o silicone industrial. Essa substância é um plástico pastoso que é inserido no corpo das travestis por uma bombadeira (uma travesti paga para injetar silicone nos corpos de outras). ${ }^{37}$ Durante uma sessão de injeção de silicone industrial, a travesti a ser bombada deita em uma cama com pedaços de tecido amarrados em sua cintura para evitar que o silicone vá para lugares não planejados. As partes mais comumente "siliconadas" são as nádegas, as coxas e os quadris. O peito não é um lugar apropriado para a injeção desse tipo de silicone, dizem as travestis, por ser um lugar "cheio de veias", o que pode ocasionar danos muito graves.

Esses processos de feminilização parecem enfatizar o fato de que a anatomia não é mais o destino da humanidade, ${ }^{38}$ já que pode ser facilmente manipulada por diferentes motivos. As mudanças corporais elaboradas pelas travestis afirmam que identidade (especialmente a identidade de gênero) é uma questão de estilo de vida e escolha, não de essência. Além disso, e talvez o aspecto mais relevante para este estudo, esses processos demonstram que o corpo não pode ser considerado como um meio passivo sobre o qual significados sociais são impostos. Devese, pelo contrário, considerar o corpo como um participante ativo na construção de significados. Assim, ao manipular as formas masculinas de seus corpos, as travestis incorporam significados de gênero polimorfos que são perpetuados socialmente e, como será discutido na próxima seção, lingüisticamente.

\section{Supercompensação de gênero: a pre- ferência das travestis pelo feminino gramatical}

A complexidade das práticas sociais das travestis descritas até este ponto parece moldar as maneiras que esses transgêneros utilizam a linguagem. Esta seção traz a análise de como as travestis participantes da CdeP investigada usam o sistema gramatical de gênero como uma ferramenta discursiva versátil para manipular suas possibilidades identitárias. As travestis parecem empregar 
${ }^{39}$ HALL, 2002, p. 140.

40 Emmanuel SCHEGLOFF, Gail JEFFERSON e Harvey SACKS, 1997. o gênero morfológico para elaborar uma complexa atividade de fragmentação de suas identidades.

Gramaticalmente, a palavra travesti é descrita como um substantivo masculino. Porém, o uso feito dessa palavra e de pronomes, adjetivos e substantivos para se referir a travestis demonstra que na comunidade estudada formas femininas são a escolha preferida, não-marcada entre as informantes. Essa é uma estratégia lingüística utilizada por diferentes comunidades de transgêneros no mundo a qual Kira Hall ${ }^{39}$ chama de "supercompensação de gênero", ou seja, a subversão das determinações gramaticais para a construção de uma identidade de gênero discursivo consistente com as performances generificadas dos indivíduos em tais comunidades. Assim, com base no uso real da língua por travestis, consideramos a utilização de formas masculinas para se referir a travestis como uma escolha marcada e, com isso, identificamos os padrões de uso desses termos.

A preferência pelo feminino gramatical tornou-se evidente já no início do trabalho de campo, conforme o demonstra o excerto abaixo.

\section{Excerto 2 [LIB 1653 - FTCLSR]: preferência êmica pelo feminino gramatical}

341 ROD: $\quad$ E tu Thalia (.) Como é que tu definiria o

342 travesti? =

343 SANDRA: =OLHA AQUI Ó (.) Vamo entrá no nívelnum nível

344 assim (.) Pra tu se enquadrá com a gente não é 0

345 tra[ves]ti (.) A travesti.

346 ROD: ok

347FABÍOLA: [@@@@]

348 ROD: [Tá certo] me desculpa. Desculpa.

Rodrigo, em sua pergunta (linha 341), usa a palavra travesti como um substantivo masculino. Antes mesmo de receber a resposta, Sandra, uma membra da ONG Liberdade, responde à questão com a mais "despreferida" forma de reparo - o reparo efetuado por outro/a que não o/ a falante que cometeu o erro,$-{ }^{40}$ na qual corrige o mau uso de travesti (no masculino) (linhas 343-345). É importante notar que Sandra elabora tal correção na tentativa de tornar Rodrigo um membro da comunidade; ou seja, se quisesse "se enquadrar com elas", deveria usar a "mesma língua". Dessa maneira, fica evidente que as participantes da 
${ }^{41}$ OLIVEIRA, 1994; Suzana LOPES, 1995; Hélio SILVA e Cristina FLORENTINO, 1996; BENEDETTI, 2000 e 2005; e Larissa PELÚCIO, $2005 a$ e $2005 b$.

42 KULICK, 1998.

${ }^{43}$ KULICK, 1999, p. 612. comunidade investigada têm consciência do poder da língua de (re)produzir e/ou (re)criar identidades. Além disso, também fica claro, na interação acima, que é o feminino gramatical, e não o masculino, a escolha preferida para se referir às travestis.

Partindo, então, do pressuposto de que formas gramaticais femininas são a escolha das travestis para referirem a si mesmas e a outras travestis, mas, ao mesmo tempo, observando que durante as entrevistas as informantes ainda utilizavam formas masculinas quando descreviam alguns eventos em particular, dedicamo-nos a investigar os contextos nos quais o masculino gramatical era utilizado. Em outras palavras, a pergunta de pesquisa que nos movia era: já que as travestis fazem questão do uso do feminino, por que, em algumas circunstâncias, ainda fazem uso do masculino?

Estudos prévios sobre travestis têm muitas vezes negligenciado a importância do sistema lingüístico na produção da identidade desses sujeitos. ${ }^{41}$ Uma exceção a essa tendência é a etnografia sobre travestis em Salvador elaborada pelo antropólogo Don Kulick, ${ }^{42}$ que coloca sob escrutínio a relevância da linguagem na fabricação da identidade das travestis. Ainda assim, contudo, há algumas generalizações sobre o uso do gênero gramatical no estudo de Kulick que não se aplicam às práticas observadas no grupo de travestis investigado na região Sul do Brasil. Kulick afirma que, "quando as travestis utilizam a palavra travesti para falar do grupo como um todo, elas parecem guiadas pela gramática e usam formas masculinas [...] que concordam com travesti". ${ }^{43}$

As travestis da Cidade do Sul não somente usam formas masculinas para se referir às travestis "como um grupo". Elas utilizam o sistema gramatical de gênero de maneiras altamente sofisticadas para construir uma miríade de significados sociais que parecem estar relacionados com sua corporificação de símbolos femininos sobre uma base biológica masculina.

Depois de analisar todas as ocorrências de substantivos, adjetivos e pronomes masculinos utilizados pelas travestis para referir a si mesmas e a outras travestis, observamos que tal uso acontece em quatro contextos discursivos distintos, descritos a seguir.

\section{Narrativas do eu anterior às mudanças corporais}

O primeiro, e talvez o mais óbvio, uso do masculino gramatical acontece quando as travestis falam sobre si antes de suas mudanças corporais, ou seja, antes de terem 
incorporado a travestilidade. Isso pode ser visto no excerto que segue.

\section{Excerto 3 [LIB953 - CLCR]}

784 CYNTHYA: Isso tem até num livro que eu li na na minha 785 infância. Quando eu era reprovado, meu pai me deixava de castigo. Eu ficava numa biblioteca lendo que falava da infância e da fase adulta

No excerto acima, vemos Cynthya falando de sua infância (período pré-travesti), quando ela costumava ser castigada por seu pai por ser reprovada na escola. Ela se refere ao eu que fora reprovado na escola no gênero gramatical masculino.

Outro exemplo desse padrão de uso da língua é apresentado no excerto 4, a seguir.

\section{Excerto 4 [LIB 1653 - JCMSR]}

104 JOANA: =Foi natural. Até porque isso vem de berço.

105 Desde de pequeno. Eu sempre brinquei de bonecas.

106 Vestia os vestido da minha mãe, das minha tia.

No excerto 4, Joana descreve a travestilidade como algo que a acompanha desde o berço. Ela justifica essa idéia ao reportar que desde muito cedo em sua infância costumava brincar com jogos comumente associados a meninas (i.e., bonecas). Além disso, costumava usar as roupas de sua mãe e tias. Porém, ao se referir a si mesma quando criança, ela utiliza o masculino, i.e., "desde pequeno".

Esse padrão de uso da forma masculina tem a ver, de acordo com as informantes, com dois fatos. Primeiramente, o fator mais evidente é que as travestis referem-se à época de sua vida anterior às mudanças corporais, já que naquele momento não tinham ainda moldado seus corpos com hormônios e silicone; ou seja, "a travesti não era feita". Assim, o sistema gramatical de gênero é empregado para marcar dois estágios distintos na identidade travesti: formas masculinas identificando seu período como machos (em sexo e performance) e formas femininas para indicar sua travestilidade. 
O segundo fator, freqüentemente citado pelas informantes, é que as travestis cambiam para formas masculinas quando falam sobre suas vidas pré-travestilidade como signos indiciais de apego emocional a sua criação dentro da esfera familiar. Esse apego é também refletido nos excertos 5 e 6 abaixo.

\section{Discurso reportado ao falar de travestis}

Outro uso do masculino gramatical acontece quando as travestis reportam o discurso produzido por outros/as para descrever a comunidade da qual participam, como 0 excerto seguinte evidencia.

\section{Excerto 5 [LIB1653 - FTCLSR]}

1123 FABíOLA: Às vezes dizem assim "é porque as bichas, os

1124 travestis não gostam de mulher." Dizem tu não

1125 gosta de mulher. Mas como eu não vô gostá de

1126 mulher? Eu me identifico com ELAS né? As

1127 mulheres são minhas AMIGAS. Eu me identifico

1128 com elas.

No excerto 5, Fabíola reporta o que outras pessoas dizem sobre travestis, mais especificamente, que travestis não gostam de mulheres. Ela refuta essa acusação ao dizer por quais razões necessariamente tem de gostar das mulheres, reiterando que ela se identifica com elas. abaixo.

Esse fenômeno pode igualmente ser visto no exemplo

\section{Excerto 6 [LIB3053 - MACSR]}

258 MARCELA: Tu vê, nós tamos em 2003 né e a- a nossa sociedade questiona a maneira que a gente se veste. Mas se uma menina anda quase nua no centro todo mundo acha lindo. "Ah que coisa mais linda", né? Agora se somos nós né "por que 
Ao descrever as reações da sociedade em relação às travestis, a mais velha ativista da ONG Liberdade, Marcela, reporta o que as pessoas dizem sobre o fato de as travestis exibirem partes de seus corpos publicamente. Ela faz essa descrição usando discurso reportado direto e traz à sua explicação a masculinidade que a sociedade impõe às travestis ao utilizar termos masculinos em sua narrativa. É importante notar que Marcela não tenta subverter as opiniões sobre sua categoria e usa o masculino para expressar os estereótipos das travestis construídos pela população em geral.

$\mathrm{O}$ que parece mais interessante nesse contexto discursivo de uso de formas masculinas é que, além do fato de o que estar sendo reportado ser o que outras pessoas (que não as travestis) têm dito sobre a imagem social das travestis, essas são afirmações com as quais as próprias informantes não se alinham. Porém, as falantes não parecem capazes de se distanciar desses estereótipos (mas têm a possibilidade de usar o feminino gramatical para se construir de maneira diferente) e aceitam tais opiniões sem resistir a elas.

Interessantemente, no excerto 5, apesar de a palavra travesti vir imediatamente após uma palavra feminina usada para descrever homossexuais em geral (i.e., as bichas), o masculino gramatical ainda é empregado. Parece que, embora as travestis estejam sempre prontas para corrigir aqueles/as que a elas se referem no masculino, visões sociais sobre travestis estão tão fortemente enraizadas que elas não são capazes de modificar esse fato em seu discurso. Assim, ao reportar opiniões de outras pessoas sobre as travestis, elas não desafiam os estereótipos de sua comunidade como sujeitos masculinos. Travestis, dessa maneira, reproduzem e perpetuam discursos sobre seu grupo através da maneira com que usam a linguagem.

\section{Descrição de si dentro da esfera familiar}

As travestis também fazem uso do masculino gramatical para descrever-se dentro de suas relações familiares, como os excertos 7 e 8 apontam.

\section{Excerto 7 [LIB1653 - FTCLSR]}

453 THALIA: = Mãe é mãe. Ela sabe que a gente nunca não vai

454 sê uma mulher pra elas. A gente vai sê um 


$\begin{array}{ll}455 & \begin{array}{l}\text { filho } \\ \text { home. Como ela sofreu pra ganhá todas as } \\ \text { gentes }\end{array} \\ 456 & \begin{array}{l}\text { né? Ele- como eu eu fui o eu sô o filho mais } \\ \text { velho, ela quase morreu quando ela foi me }\end{array} \\ 457 & \begin{array}{l}\text { ganhá. } \\ 458\end{array} \\ 459 & \begin{array}{l}\text { Por eu sê assim. A minha família me aceita do } \\ \text { jeito que eu sô }\end{array}\end{array}$

Como podemos ver acima, Thalia narra as concepções de sua mãe sobre sua identidade de gênero - uma vez homem, para sempre homem. Thalia acriticamente reporta que uma mãe nunca considerará sua filha travesti como uma mulher.

Abaixo, vê-se Joana fazendo uso similar do masculino gramatical para referir a si mesma dentro da esfera familiar.

\section{Excerto 8 [LIB1653 - JCMSR]}

119 JOANA: Por respeito a ela (a mãe de Joana) eu não uso

120 roupa de mulher. TENHO TODAS AS MINHAS ROUPAS

121 lá. Ela sabe que eu tenho INÚMERAS roupas ma::s

122 de casa eu não saio vestido de mulher.

123 RODRIGO: Sim. Tu sai e te veste em outro [lugar]

124 JOANA: [É] me visto em

125 outro lugar.

Embora descreva o fato de se vestir como mulher, Joana reporta que, por respeito a sua mãe, ela não sai de casa vestida assim. Ao descrever esse fato, refere-se a si mesma no masculino.

O que mais chama a atenção sobre esse uso do sistema de gênero gramatical é a consciência das travestis sobre a imagem de "perversão" ligada a sua comunidade. Em outras palavras, o uso do masculino gramatical dentro de tais contextos discursivos demonstra como a construção lingüística da identidade travesti é afetada por construções ideológicas de sua imagem na sociedade brasileira. Ao usar formas masculinas em contextos discursivos nos quais reiteram seu respeito com suas famílias, principalmente com suas mães, as travestis parecem aceitar tal ideologia sobre sua comunidade. As informantes mostram-se, assim, preocupadas com a imagem que projetam para suas famílias. Embora algumas famílias aceitem sua nova identidade, as travestis se autodescrevem como seres 
${ }^{44}$ Erving GOFFMAN, 1959. masculinos ao relatar sobre sua relação com mães, pais, irmãs, irmãos, etc.

\section{Contraste eu vs. os outros: uma estraté- gia para proteger a face}

Finalmente, o contexto discursivo mais revelador do uso do masculino pelas travestis neste estudo é aquele em que as entrevistadas fazem questão de distinguir-se de outras travestis. Nesta última categoria, a travesti refere-se a outras membras de sua comunidade no masculino quando descreve eventos negativos nos quais aquelas travestis estiveram envolvidas. Esse contexto discursivo, assim como o anterior, parece constituir uma estratégia discursiva de construção de uma imagem "de respeito" para a falante. Em outras palavras, as informantes projetam uma imagem pública positiva (i.e., face) ${ }^{44}$ para si mesmas ao contrapor 0 "eu" (usado no feminino) ao "outro" ou "outros" (usado no masculino) para se referir a outras travestis com as quais a falante não se identifica. Esse fenômeno pode ser verificado nos excertos abaixo.

\section{Excerto 9 [LIB953 - CLCR]}

1356 CYNTHYA: Eu acho que não há a a necessidade de você tá:: colocando o teu corpo à mostra, os teus atributos. Porque muitas vezes tu tem que avaliá assim ó. Assim como essas pessoas se sentem ofendidas agredidas por uma visão corporal, ela

elas sabem que não- por mais que seja um aspecto feminino não é uma mulher e:: muitas vezes assim ó. No MEU caso eu tenho família eu tenho meu sobrinho meus eu tenho irmã e eu:: sempre manten- mantive um pa- um padrão de de educacional da minha- dos meus familiares. De forma que nunca os agredisse. Agora sempre eu acho que pra tudo existe um local pra se fazê isso. Eu não gostaria que a minha sobrinha ou meu sobrinho passasse numa avenida e tivesse

1371 uma prostituta ou um travesti exposto, expondo

1372 sua genitália ou algo mais. 
${ }^{45}$ GOFFMAN, 1959.

Nesse excerto, Cynthya usa a forma masculina para se referir a travestis que não merecem ter sua feminilidade reconhecida - aquelas que expõem sua genitália em espaços públicos. Nesse contexto discursivo, Cynthya parece estar usando de uma estratégia de proteção de face..$^{45}$ Ao construir uma identidade negativa para travestis envolvidas em eventos como no descrito acima (usando formas masculinas), Cynthya firma uma identidade positiva para si (usando, ao contrário, formas femininas). Em outras palavras, as travestis envolvidas nos eventos avaliados como negativos pela falante têm sua feminilidade negada por ter um comportamento com o qual a falante não se alinha.

Abaixo vemos outra travesti, Fabíola, fazendo uso do masculino gramatical de uma maneira semelhante.

\section{Excerto 10 [LIB1653 - FTCLSR]}

1413 CASSIANA: =É:: era aquela coisa que tinha muito

1414

1415 FABÍOLA:

1416 glamour né? Hoje em dia [não.]

1416
[Tinha] tinha-

1417 1418 travesti era LUXO. Mas hoje em dia não hoje tá muito vulgarizado. Porque eles mesmo deturparam a classe.

Ao falar de travestis no plural masculino, enquanto faz uma crítica, Fabíola não está simplesmente fazendo uma generalização sobre as "travestis como um grupo". Ela fala especificamente sobre algumas travestis: aquelas que se "vulgarizam" e que "deturpam a classe", travestis essas com as quais Fabíola não se identifica.

O que parece mais surpreendente nesse contexto discursivo de uso do masculino gramatical é que, apesar de as travestis estarem falando sobre uma comunidade à qual elas pertencem, a comunidade travesti, elas estão se referindo a um tipo específico de travestis, aquelas com cujas certas práticas elas não se alinham. Nesse último contexto discursivo de uso do masculino, o gênero gramatical de certa forma opera como um marcador de exclusão da falante de certo grupo de travestis.

Observamos, então, que a manipulação do sistema

${ }^{46}$ LOURO, 2001.

${ }^{47}$ MAUSS, 1996. de gênero gramatical é fruto de dois fatores. 1) Por viver nas fronteiras dos gêneros, ${ }^{46}$ as travestis incorporam, através do sofisticado sistema de techniques du $\operatorname{corps}^{47}$ descrito acima, significados associados ao masculino (sua biologia) e ao feminino (sua nova identidade) não apenas em seus corpos, mas também em seu discurso. Com isso, elas têm a 
${ }^{48}$ Tal proposta já foi elaborada por um grupo de coordenadoras de ONGs de travestis em reuniões com representantes do governo em Brasília. Nessa reunião, foi concordado que, em documentos oficiais, os termos utilizados em referência às travestis devem ser utilizados no feminino. oportunidade de explorar as duas facetas descontínuas de sua identidade (a biológica e a social) para fragmentar lingüisticamente seus papéis sociais. Porém, essa polimorfia discursivo-identitária não pode ser somente considerada como produto de seus corpos transgêneros. Como visto acima, 2) discursos sobre a masculinidade e a feminilidade também têm um papel importante nesse processo lingüístico de construção da identidade travesti. Ao se referirem a outras travestis no masculino, as falantes não parecem influenciadas por determinações gramaticais, já que facilmente as subvertem com o uso do feminino. As narrativas das travestis neste estudo são moldadas por ideologias que associam o masculino e o feminino a específicas características sociais.

\section{De volta ao trottoir: discutindo o uso das formas masculinas com as travestis}

Como um estágio complementar da investigação, os resultados encontrados foram levados a uma das reuniões semanais organizadas pela ONG Liberdade para que fossem discutidos com as travestis. Nosso objetivo principal era comparar suas reações aos usos do masculino gramatical com as categorias analíticas a que chegamos, enquanto sociolingüistas e analistas do discurso.

Primeiramente, foi-lhes proposta uma breve discussão sobre o uso de formas masculinas vs. femininas para se autoreferirem. As informantes presentes na reunião mostraram consciência das determinações gramaticais da palavra travesti, como demonstra o exemplo abaixo.

\section{Excerto 12 [notas de campo]}

SUSI: O correto é $O$ travesti. Se não nos chamariam de bicha burra.

Como podemos ver, Susi descreve as implicações trazidas pelo uso do feminino, i.e., que as travestis desconhecem o Português normativo. Por outro lado, elas também demonstraram seu esforço consciente para modificar esse fato, afirmando que "elas deveriam fazer uma proposta para mudar a língua". ${ }^{48} \mathrm{O}$ que claramente vemos aqui é que as travestis estão em tensão entre duas forças: em um dos extremos, o desejo de subverter a gramática normativa ao transformar a palavra travesti em um substantivo feminino; no outro extremo, a consciência de que qualquer ação de sua parte para tal mudança pode ser usada contra elas - com as acusações de falta de 
conhecimento sobre sua própria língua. Qualquer dos extremos dessa tensão demonstra as forças ideológicas em funcionamento na sociedade em relação às travestis, ou seja, as forças opostas ao reconhecimento de sua feminilidade assim como a imagem intelectual derrogatória imposta sobre elas - subversão lingüística crítica da língua por parte das travestis é renomeada pela sociedade como ignorância.

Após discutir os usos do masculino e do feminino gramaticais, excertos de transcrições foram entregues às travestis. Nesses excertos incluíram-se alguns dos exemplos de uso do masculino gramatical encontrados no corpus. As categorias não foram apresentadas às travestis, já que o objetivo dessa reunião era verificar o que as travestis teriam a dizer sobre seu uso inconstante do gênero gramatical. Dessa forma, as transcrições que elas receberam não estavam etiquetadas com as categorias por nós formuladas.

Na discussão sobre seus usos de formas masculinas, com exceção do uso do masculino para reportar o que outros falam sobre travestis, todas as outras formas coincidiram com a interpretação dos dados reportada aqui. Assim, a volta ao trottoir foi um exercício de triangulação dos resultados no qual as travestis, de sua maneira, explicaram seus usos do sistema gramatical de gênero como um produto de discursos sobre os gêneros que moldam nossa experiência como seres generificados na sociedade brasileira.

\section{Considerações finais}

Este estudo investigou como travestis que se prostituem em uma região urbana do Sul do Brasil manipulam o sistema gramatical de gênero em Português para multifacetar suas identidades como transgêneros com o intuito de produzir uma miríade de significados sociais à sua construção de identidade. O sistema polimorfo de técnicas corporais que as travestis fazem uso para moldar suas identidades e senso de si foi caracterizado, e suas tentativas de estruturar sua posição-de-sujeito na sociedade brasileira foram analisadas. Em uma sociedade fortemente baseada na compreensão tradicional dicotômica de gênero, pessoas que sobrepõem as práticas semióticas para construção generificada de sua identidade são limitadas por ideologias sobre sua comunidade (e sobre as posições de gênero disponíveis) e, assim, não conseguem utilizar suas preferências lingüísticas consistentemente.

Com o intuito de explorar as potencialidades de sua posição, as travestis alternam do feminino gramatical para - masculino para incorporar discursos sobre a masculinidade hegemônica. Isso pode ser visto nos contextos 
${ }^{49}$ CSORDAS, 1990, p. 36.

50 GOFFMAN, 1959. discursivos em que a travesti utiliza formas masculinas para se referir a travestis com as quais ela não se identifica e formas femininas para se referir a si mesma, distanciando-se do estereótipo de travestis como pessoas violentas.

Os padrões de língua encontrados na comunidade investigada demonstram que a corporificarão de valores femininos sobre um corpo biologicamente masculino dá às travestis uma ambigüidade inegável que é perpetuada em suas práticas sociais e reafirmada lingüisticamente. Ao remodelar e reinterpretar seus corpos, as travestis incorporam ideologias sobre a feminilidade e a masculinidade em suas negociações de gênero. Dessa forma, as travestis fortalecem sua polimorfia social, que está também presente em seu discurso. Como afirma Thomas Csordas, "os corpos não são apenas objetos para nós; eles são uma parte integrante do sujeito". ${ }^{49}$

Os corpos das travestis, portanto, transcendem o status de suporte passivo para suas modificações sociais; eles se tornam participantes ativos na construção de significados sociolingüísticos. Esse fato reitera as idéias de Erving Goffman ${ }^{50}$ sobre o corpo como um mediador entre nossa auto-identidade e nossa identidade social. No caso das travestis, isso é evidente através das práticas discursivas descritas neste artigo. A fluidez das travestis em variados âmbitos da sexualidade e dos gêneros as torna capazes de extrair significados sociais de visões mais amplas sobre a masculinidade e a feminilidade na sociedade brasileira e de alocar esses significados sobre os processos de construção lingüística de sua identidade.

Para finalizar, gostaríamos de sugerir que, para que aprofundemos a compreensão sobre as ligações entre gênero, sexualidade e linguagem (especificamente no caso dos/as transgêneros, mas não restrito a eles/as), consideremos como usuários/as da língua incorporam discursos locais sobre gênero e sexualidade em seus corpos e como essa corporificação os/as capacita a moldar seu uso de língua de acordo com as ideologias circundantes sobre esses construtos. Assim, concordamos com Keith Walters quando afirma "que sociolingüistas [deveriam] reconhecer que o corpo de cada falante, também socialmente construído, simultaneamente permite e regula os padrões de uso de língua dos sujeitos de maneiras complexas". ${ }^{51}$ Como foi discutido aqui, esse fato pode ser visto nas formas sofisticadas através das quais as travestis manipulam seus corpos e seu discurso para se (trans)generificar. 


\section{Referências bibliográficas}

BENEDETTI, Marcos R. "Hormonizada: reflexões sobre o uso de hormônios e tecnologia do gênero entre travetis em Porto Alegre". In: FABREGAS-MARTINEZ, Ana Isabel; BENEDETTI, Marcos (Orgs.). Na batalha: identidade, sexualidade e poder no universo da batalha. Porto Alegre: Da Casa Editora/GAPA-RS, 2000. p. 47-62.

. Toda feita: o corpo e o gênero das travestis. Rio de Janeiro: Garamond, 2005.

BESNIER, Niko. "Crossing Genders, Mixing Languages: The Linguistic Construction of Transgenderism in Tonga." In: HOLMES, Janet Holmes, and MEYERHOFF, Miriam (eds.). Handbook of Language and Gender. Oxford: Blackwell, 2003. p. 279-301.

BORBA, Rodrigo, and OSTERMANN, Ana C. "Do Bodies Matter? Travestis' Embodiment of (Trans)Gender Identity through the Manipulation of the Brazilian Portuguese Grammatical Gender System." Gender and Language, v. 1, 2007. p. 131-147.

BOURDIEU, Pierre. "The Social Space and the Genesis of Groups." Theory and Society, v. 14, 1985. p. 723-744.

."The Forms of Capital." In: RICHARDSON, John (ed.). Handbook of Theory and Research for the Sociology of Education. New York: Greenwood Press, 1986. p. 241-325. BUCHTOLZ, Mary, and HALL, Kira. "Language and Identity." In: DURANTI, Alessandro (Org.), A Companion to Linguistic Anthropology. Oxford: Basil Blackwell, 2003. p. 268-294. . "Theorizing Identity in Language and Sexuality Research." Language in Society, v. 33, 2004. p. 469-515. . "Identity and Interaction: A Sociocultural Linguistic Approach." Discourse Studies, v. 7, n. 4-5, 2005. p. 585614.

BUNZL, Matti. "Inverted Appellation and Discursive Gender Insubordination: An Austrian Case Study in Gay Male Conversation." Discourse and Society, v. 11 , 2000. p. 207236.

BUTLER, Judith. Problemas de gênero: feminismo e subversão da identidade. Tradução: Renato Aguiar. Rio de Janeiro: Civilização Brasileira, 2003.

CAMERON, Deborah. Working with Spoken Discourse. London: Sage, 2001.

COATES, Jennifer. "'Thank God I'm a Woman': The Construction of Differing Femininities." In: CAMERON, Deborah (ed.). The Feminist Critique of Language: A Reader. 2nd. ed. London: Routledge, 1998. p. 297-320.

CSORDAS, Thomas. "Embodiment as a Paradigm for Anthropology." Ethos, v. 18, 1990. p. 5-47. 
DU BOIS, John. W., SCHUETZE-COBURN, Stephan, PAOLINO, Danae, and CUMMING, Susana (eds.). Discourse Transcription. Santa Barbara, CA: University of Santa Barbara, 1992.

DURANTI, Alessandro. "Linguistic Anthropology: History, ldeas, and Issues." In: DURANTI, Alessandro (ed.). Linguistic Anthropology: A Reader. Oxford: Blackwell, 2001. p. 138.

ECKERT, Penelope, and MCCONNELL-GINET, Sally. "Think Practically and Look Locally: Language and Gender as Community-Based Practice." Annual Review of Anthropology, v. 21, 1992. p. 461-490.

. "New Generalizations and Explanations in Language and Gender Research." Language in Society, v. 28, 1999. p. 185-201.

Language and Gender. Cambridge: Cambridge University Press, 2003.

EPPLE, Carolyn. "Coming to Terms with Navajo Nadleehi: A Critique of Berdache, 'Gay', 'Alternative Gender', and 'Two Spirit'." American Ethnologist, v. 25, n. 2, 1998. p. 267290.

GIDDENS, Anthony. A transformação da intimidade: sexualidade, amor e erotismo nas sociedades modernas. São Paulo: Editora da Unesp, 1993.

GOFFMAN, Erving. The Presentation of Self in Everyday Life. New York: Doubleday, 1959.

GOULET, Jean-Guy. "The 'Berdache' - 'two-spirit': A Comparison of Anthropological and Native Constructions of Gendered Identities among the Northern Athapaskans." The Journal of the Royal Anthropological Institute, v. 2, 1997. p. 683-701.

HALL, Kira, and O'DONOVAN, Veronica. "Shifting Gender Positions Among Hindi-speaking Hijras." In: BERGVALL, Victoria, BING, Janet, and FREED, Alice (eds.). Rethinking Language and Gender Research: Theory and Practice. London: Longman, 1996. p. 228-266.

HALL, Kira. "'Go Suck your Husband's Sugarcane!' Hijras and the Use of Sexual Insult." In: LIVIA, Anna, and HALL, Kira (eds.). Queerly Phrased: Language, Gender, and Sexuality. New York: Oxford University Press, 1997. p. 430460.

. "'Unnatural' Gender in Hindi." In: HELLINGER, Marlis, and BUSSMAN, Hadumod (eds.). Gender across Languages: The Linguistic Representation of Women and Men. Amsterdam: John Benjamins, 2002. p. 133-162.

"Intertextual Sexuality: Parodies of Class, Identity, and

Desire in Liminal Delhi." Journal of Linguistic Anthropology, v. 15, n. 1, 2005. p. 125-144. 
HOLMES, Janet, and MEYERHOFF, Miriam. "The Community of Practice: Theories and Methodologies in Language and Gender Research." Language in Society, v. 28, 1999. p. 173-183.

KROSKRITY, Paul V. Regimes of Language: Ideologies, Policies, and Identities. Santa Fé, MN: School of American Research Press, 2000.

KULICK, Don. "Causing a Commotion: Scandal as Resistance among Brazilian Travesti Prostitutes." Anthropology Today, v. 12, 1996. p. 3-7.

. "The Gender of Brazilian Transgendered Prostitutes." American Anthropologist, v. 99, 1997. p. 547-585.

. Travesti: Sex, Gender, and Culture among Brazilian Transgendered Prostitutes. Chicago and London: University of Chicago Press, 1998.

. "Transgender and Language: A Review of Literature and Suggestions for the Future." Journal of Lesbian and Gay Studies, v. 5, 1999. p. 601-622.

LEVY, Robert. "The Community Function of Tahitian Male Transvestism: A Hypothesis." Anthropological Quarterly, v. 44, n. 1, 1971. p. 12-21.

LIVIA, Anna. "Disloyal to Masculinity: Linguistic Gender and Liminal Identity in French." LIVIA, Anna, and HALL, Kira (eds.). Queerly Phrased: Language, Gender, and Sexuality. New York: Oxford University Press, 1997. p. 349368.

LOPES, Suzana Soares da Silva. "Corpo, metamorfose e identidades - de Alan a Elisa Star". In: LEAL, Ondina Fachel (Org.). Corpo e significado: ensaios de antropologia social. Porto Alegre: Editora da UFRGS, 1995. p. 227-231.

LOURO, Guacira Lopes. "Teoria 'queer': uma política pósidentitária para a educação". Revista Estudos Feministas, v. 9, n. 2, p. 541-553, 2001.

MAGEO, Jeannette M. "Male Transvestism and Cultural Change in Samoa." American Ethnologist, v. 19, n. 3, 1992. p. 443-459.

MAUSS, Marcel. "Les techniques du corps". In: MAUSS, Marcel (Org.). Sociologie et Antropologie. Paris: PUF, 1996. p. 363368.

MOITA LOPES, Luiz Paulo. Identidades fragmentadas: a construção discursiva de raça, gênero e sexualidade em sala de aula. Campinas: Mercado de Letras, 2002.

. Discursos de identidades: discurso como espaço de construção de gênero, sexualidade, raça, idade e profissão na escola e na família. Campinas: Mercado de Letras, 2003. 
OLIVEIRA, Marcelo José. Jogo de cintura: uma etnografia sobre travestis em Florianópolis. Florianópolis: Departamento de Ciências Sociais, UFSC, 1994. Mimeo.

OSTERMANN, Ana Cristina "Communities of Practice at Work: Gender, Facework, and the Power of Habitus at an AllFemale Police Station and a Crisis Intervention Center in Brazil." Discourse \& Society, v. 14, n. 4, 2003. p. 473-505.

. "Comunidades de prática: gênero, trabalho e face". In: HEBERLE, Viviane M.; OSTERMANN, Ana Cristina; FIGUEIREDO, Débora de Carvalho (Orgs.). Linguagem e gênero no trabalho, na mídia e em outros contextos. Florianópolis: Editora da UFSC, 2006. p. 15-47.

PARKER, Richard G. Abaixo do Equador: culturas do desejo, homossexualidade masculina e comunidade gay no Brasil. Rio de Janeiro: Record, 2002.

PELÚCIO, Larissa. "Na noite nem todos os gatos são pardos: notas sobre a prostituição travesti". Cadernos Pagu, v. 25 , p. $217-248,2005 a$.

“'Toda quebrada na plástica': corporalidade e construção de gênero entre travestis paulistas". Campos, v. 6, n. 1, p. 97-112, 2005b.

PERES, Wiliam S. "Travestis: subjetividades em construção permanente". In: UZIEL, Anna P.; RIOS; Luís F.; PARKER, Richard G. (Orgs.). Construções da sexualidade: gênero, identidade e comportamento em tempos de aids. Rio de Janeiro: Pallas, 2004. p. 115-128.

SCHEGLOFF, Emmanuel A., JEFFERSON, Gail, and SACKS, Harvey. "The Preference for Self-Correction in the Organization of Repair in Conversation." Language: Journal of the Linguistic Society of America, v. 53, 1977. p. 361-382.

SILVA, Hélio R. S. Travesti: a invenção do feminino. Rio de Janeiro: Iser, 1993.

. Certas cariocas: travestis e a vida de rua no Rio de Janeiro. Rio de Janeiro: Relume-Dumará, 1996.

SILVA, Hélio R. S.; FLORENTINO, Cristina de Oliveira. "A sociedade dos travestis: espelhos, papéis e interpretações". In: PARKER, Richard; BARBOSA, Regina Maria (Orgs.). Sexualidades brasileiras. Rio de Janeiro: Relume-Dumará, 1996. p. 105-118.

SINNOT, Megan. Toms and Dees: Transgender Identity and Female Same-Sex Relationships in Thailand. Honolulu: University of Hawai'l, 2004.

WALTERS, Keith. "'Opening the Door of Paradise a Cubit”: Educated Tunisian Women, Embodied Linguistic Practice, and Theories of Language and Gender." In: BUCHOLTZ, Mary, LIANG, A. C., and SUTTON, Laurel (eds.). Reinventing Identities: The Gendered Self in Discourse. New York: Oxford University Press, 1999. p. 200-217. 
WIKAN, Unni. "The Omani Xanith: A Third Gender Role?" Man, v. 13, n. 3, 1978. p. 473-475.

[Recebido em março de 2007 e aceito para publicação em julho de 2007]

Unlimited Gender: The Discursive Construction of the Travesti Identity Through the Manipulation of the Grammatical Gender System

Abstract: This study investigates Southern Brazilian traveestis' manipulation of the Portuguese grammatical gender system. During field work, it was verified that feminine forms are the preferred choice in the group. However, ideological and bodily tensions that surround travestis seem to force them to make use of masculine forms in specific discursive contexts. Travestis use masculine forms 1) to produce narratives about the time before their body modifications took place; 2) to report speech produced by others when talking about transvestites; 3) to talk about themselves within their family relationships; and 4) to distinguish themselves from 'other' travestis they do not identify with. Thus, the study shows how Southern Brazilian travestis use the Brazilian Portuguese grammatical gender system as a resource to manipulate their identities and the identities of the community they belong to.

Key Words: Travestis; Transgender Identity; Grammatical Gender; Embodiment.

\section{Apêndice}

As convenções para as transcrições foram adaptadas de DU BOIS, SCHUETZE-COBURN, PAOLINO e CUMMING, 1992, e são as seguintes:

MAIÚSCULAS volume maior

Negrito parte da transcrição enfatizada para análise

entonação continuada

- $\quad$ entonação decrescente

? entonação crescente

[ ] sobreposição de fala

- $\quad$ palavra truncada

- $\quad$ enunciado truncado

$=\quad$ fala colada

:.:.: som prolongado

$>$ fala $<\quad$ fala mais rápida

$<$ fala $>$ fala mais lenta

(0.0) tempo em segundos durante o qual não há fala

(( )) informações fáticas sobre a interação

XXXX parte de fala inaudível; cada $X$ representa mais ou menos uma sílaba

FALANTE: no início de um turno de fala identifica a falante

@@@ risos 